\title{
Dynamic Accessibility: Incorporating Day-To-Day Travel Time Reliability into Accessibility Measurement
}

\author{
Konstantina Bimpou ${ }^{1, *}$ and Neil S. Ferguson a \\ a Department of Civil and Environmental Engineering, James Weir Building, University of Strathclyde, G1 1XJ, Glasgow, UK
}

\begin{abstract}
Travel times and hence accessibility in urban areas are susceptible to traffic disruption caused by events such as congestion, roadworks and traffic accidents. Being highly valued by travellers, travel time reliability affects their participation in activities and thus, plays a decisive role in accessibility. The aim of the study was to develop an approach to integrate travel time reliability into the measurement of accessibility. To achieve this, we extended a commonly-used accessibility indicator to include day-today variability in travel times. In a case study of the accessibility to the newly-built Queen Elizabeth University Hospital (QEUH) in Glasgow, we used real-time travel times with high temporal resolution collected over a long period of time to demonstrate the applicability and the utility value of this approach compared to the standard accessibility measurement. Our results revealed that travel time reliability varied both temporally and spatially, and zones experienced relatively high levels of accessibility loss due to higher travel time variability. The proposed approach provides a more realistic representation of actual network performance, allows for assessing the effect of travel time reliability on accessibility throughout the day and will help transport planners to trace equity impacts on accessibility due to travel time unreliability.
\end{abstract}

Keywords: Accessibility, Reliability, Variation, Travel time, Dynamic

\section{Acknowledgements:}

An earlier version of this paper was presented at the NECTAR Cluster 6 Workshop "Accessibility in urban modelling: from measurement to policy instruction" in Lyon, June 2018. The authors are grateful for the feedback they received from the participants during the workshop. This research was partsponsored by the BRE Trust. Finally, the authors would like to thank the reviewers for their comments and suggestions.

\section{Introduction}

Travel time reliability is a key performance metric of transport systems (Alvarez and Hadi, 2012). Thus, researchers have increasingly focussed on the measurement and interpretation of travel time reliability (Taylor, 2013). At the same time, a long list of recent research reveals considerable interest in the impact of the daily variation in travel time on accessibility (Farber, Morang and Widener, 2014; Kaza, 2015; Fransen et al., 2015; Moya-Gómez and García-Palomares, 2015), where the concept of accessibility links the performance of the transport system with the spatial (and temporal) distribution of the population (demand) and activities (supply) (Geurs and Van Wee, 2004). This study seeks to incorporate travel time reliability within the measurement of accessibility at urban or regional scale in order to identify zones or population sub-groups, which are disproportionately affected by travel time

\footnotetext{
* Corresponding author at: Department of Civil and Environmental Engineering, James Weir Building, University of Strathclyde, G1 1XJ, Glasgow, UK.

E-mail addresses: konstantina.bimpou@strath.ac.uk (K. Bimpou), n.s.ferguson@strath.ac.uk (N. S. Ferguson).
} 
unreliability. Our approach extends the measurement of potential accessibility (Hansen, 1959) using day-to-day variation in travel time obtained from mobile phone-derived data. Since the accessibility of healthcare remains in the research spotlight (Joseph and Bantock, 1982; Wang and Luo, 2005; Roberts, Blunt and Bardsley, 2014; Transport for London, 2014) due to its criticality for human life and the uneven distribution of healthcare provision (Wang and Luo, 2005) we illustrate the application of the resulting dynamic accessibility indicator in a case study centred on a newly-opened hospital in Glasgow, UK.

There are two principal sources of travel time variation in urban areas. Firstly, the normal rhythms of urban life create fluctuations in travel demand which leads to systematic variation in travel time by time of day, day of week and season. This systematic variation in travel time can be anticipated by users and shapes their perception of typical conditions (Lomax et al., 2003). The second source of travel time variation is unsystematic in nature and stems from short-term perturbations in traffic demand or capacity-reducing events (such as accidents, roadworks, parked cars, broken-down vehicles) or both. This second source introduces uncertainty into expected travel times from one day to the next and is the cause of travel time unreliability (Carrion and Levinson, 2012).

Wide use of travel time reliability in transport studies was hindered by the technical and economical difficulty of collecting travel time data at the required temporal resolution (Taylor, 2013). However, more recently, the use of GPS-equipped vehicles and the mass adoption of smart phones have yielded sources of high temporal resolution travel time data. The statistical analysis of travel time data for long periods of time is now possible meaning that the impact of travel time reliability on network performance can now be assessed without excessive cost in time or money.

Clearly, travel time reliability and accessibility - which can be loosely defined as the ease by which valued opportunities can be reached using the transport systems - are closely connected concepts (Taylor and D'Este, 2007). The probability of reaching a destination within a given travel time directly affects the level of accessibility experienced by users. It is, therefore, essential to take into account travel time reliability when measuring accessibility. So far, the effect of travel time reliability on the measurement of accessibility has not been studied to any great extent. In order to evaluate the extent to which interventions in land-use and transport systems and policy making serve our societies (Geurs and van Wee, 2004), it is essential to study how accessibility varies dynamically over time and space. Thus, the integration of travel time reliability into accessibility analysis can be regarded as a key priority.

In the following section, we summarise key literature on travel time reliability and accessibility. We then develop the proposed method for the integration of travel time reliability into accessibility. Next, we describe the case study on hospital accessibility and present the results of our analysis. In the final section, we draw conclusions and discuss implications for future research and policy.

\section{Literature Review}

\subsection{Travel Time Reliability}

\subsubsection{Definition and Measurement}

Reliability can be defined as the probability that a system performs at a certain level over a specified time period (Omer, 2013). Bell and lida (1997) identified two types of reliability - connectivity reliability and travel time reliability. Chen et al. (1999) introduced a third type: capacity reliability. Of these three types, travel time reliability, defined as the probability that travel between an origin-destination (OD) pair will be completed within a certain time, has received the most attention from researchers (Taylor and D'Este, 2007). Early reference to travel time reliability can be found in the literature dating from the 
1970s (Herman and Lam, 1974; Sterman and Schofer, 1976; Richardson and Taylor, 1978; Polus, 1979; Hall, 1983 etc.). Travel time reliability was the subject of renewed attention in the late 1990s and has gained maturity ever since (lida, 1999; Lam and Small, 2001; Van Lint and van Zuylen, 2005; National Academies of Sciences, Engineering and Medicine, 2012 etc.). Recent literature reviews of travel time reliability and its measurement can be found in Taylor (2013) and de Jong and Bliemer (2015).

Lomax et al. (2003) categorised travel time reliability metrics into three types: statistical range measures, buffer time measures and tardy trip indicators. The standard deviation and coefficient of variation have been widely used to assess travel time reliability (Herman and Lam, 1974; Bates et al., 2001; Lam and Small, 2001). However, travel time is not normally distributed and typically exhibits skewness to the right (Rakha, El-Shawarby and Arafeh, 2010; Taylor and Susilawati, 2012; National Academies of Sciences, Engineering, 2012). Taylor (2013) has argued against the use of the mean and standard deviation. Lam and Small (2001) suggested the use of median travel time instead of the mean and the difference between the 90th percentile and median instead of the standard deviation to achieve better estimations of travel time centrality and variance. Several distributions have been found to give a better fit to travel time data, among them the lognormal, Gamma, Burr, "stable" and Weibull distributions (Rakha, El-Shawarby and Arafeh, 2010; Pu, 2011; Susilawati, Taylor and Somenahalli, 2013; Taylor, 2013; Woodard et al., 2017). Still, the shape of the travel time distribution (skewness, peaks etc.) differs significantly from city to city depending on the level of aggregation (route, link, lane, traffic direction), type of modal mixture, the influence of traffic lights and bottlenecks etc. (Alvarez and Hadi, 2012). Some researchers have proposed the use of distribution-free, non-parametric measures to guard against the influence of skewed travel time data on the measurement of travel time reliability (e.g. Van Lint and van Zuylen, 2005; Kwon et al., 2011).

\subsubsection{Sources and Impact of Travel Time Unreliability}

Wang (2015) distinguished between disruptions according to frequency and severity: disasters (e.g. earthquakes) which relate to recovery, day-to-day variations in demand and/or capacity which relate to reliability and ongoing long-term changes (e.g. climate change) which relate to sustainability. Lomax et al. (2003) identified three broad categories of travel time unreliability: systemic (fluctuations in demand, traffic control devices and inadequate base capacity), planned events (work zones, special events) and unplanned events (accidents, weather). Kwon et al. (2011) studied the contribution of the sources of traffic disruption on travel time reliability and found that the effect of recurrent events predominates across the day, while non-recurrent events have a more significant contribution in the evening.

Bates et al. (2001) discussed the impact of travel time reliability on users (on-time arrival, activity engagement duration, anxiety etc.). They argued that the notion of repetition lies within reliability and therefore reliability "is closely associated with the statistical concept of variability" and that travellers perceive travel time variation as important because of the disutility of early or late arrival and the inherent cost of uncertainty. They claimed that travellers appreciate routes with lower travel time variance compared to those with lower mean travel time. The latter claim is supported by Ettema and Timmermans (2006), who found that the effect of travel time uncertainty may be greater than that of longer travel times. Thus, the provision of traffic information in reducing uncertainty affects users' route choice (Carrion and Levinson, 2012) and may affect their perception of safety margins in terms of travel times and improved accessibility (Ettema and Timmermans, 2007). Another important factor in users' perception of travel time reliability is related to their experience of the operation of the particular network (Bates et al., 2001 and Lomax et al., 2003). Regular users of a specific route have greater certainty over the travel time at specific times and days than infrequent users and are capable of detecting nonrecurrent events when experiencing abnormal travel times (Taylor, 2013). De Palma and Picard (2005) discussed travellers' behaviour under travel time uncertainty and distinguished three types of traveller: risk averse, risk neutral and risk seekers. The level of risk that travellers are willing to take in terms of 
on-time arrival is dependent on socio-economic factors such as the gender, age, employment status, mode of transport and trip purpose.

\subsection{Accessibility}

\subsubsection{Definition and Measurement}

Accessibility is a key transport planning concept which has found multiple applications since it was introduced by Hansen (1959). Specifically, accessibility analysis has been widely used to evaluate, for example, the attractiveness of major centres (hospitals, industrial zones, leisure centres etc.), potential investments (shopping centres, malls, tourist complexes etc.), transport inequalities in urban and rural areas and, more recently, transport network vulnerability. An in-depth literature review has been published by Geurs and Van Wee (2004) and recent advances in accessibility have been discussed in Geurs, De Montis and Reggiani (2015).

Accessibility reflects a joint quality of the transport network and the land use system. In line with the four components of accessibility (transportation, land-use, temporal and individual) descried by Geurs and Van Wee (2004), accessibility was defined by Taylor and D'Este (2007) as the ease by which travellers are able to reach a destination(s) in order to meet a need or want using the transport system. Six decades after its introduction a range of accessibility indicators of varying complexity can be found in the literature (Törnqvist, 1970; Weibull, 1976; Wang, 2000 etc.). Geurs and Van Wee (2004) defined five general criteria that an appropriate accessibility indicator should comply with and categorised accessibility indicators into four groups: infrastructure-based measures, location-based measures, person-based measures and utility-based measures.

\subsubsection{Non-static Accessibility Indicators}

Research has focussed increasingly on travel time uncertainty and within-day variation of accessibility (see, for example, Ettema and Timmermans, 2007; Feng, Rasouli and Timmermans, 2013; Boisjoly and El-Geneidy (2016) and Moya-Gómez et al. (2018)). Time-dependent accessibility measurement is a recent trend in accessibility studies. Time-dependent accessibility indicators measure accessibility at distinct times across the day and are divided into those reflecting travel time variation throughout the day but with invariant activity supply (Farber, Morang and Widener (2014), Kaza (2015), Fransen et al. (2015) and Moya-Gómez and García-Palomares (2015)) and those combining time-varying travel deterrence and activity supply (Farber and Fu, 2017 and Moya-Gómez et al., 2018). At their core, these studies attempted to address the unrealistic assumption made in many previous accessibility studies that travel times are static. Stępniak et al. (2019) examined the precision of the accessibility measurement in relation to the temporal resolution and found that using time intervals of less than 15 minutes did not improve it.

The literature on the day-to-day variation in accessibility is limited. Cui and Levinson (2018) used GPS data collected over a year to study the variation in the number of opportunities that could be reached within specified time intervals. Similarly, Chen et al. (2017) created accessibility measures based on different levels of probability of arriving at a destination on time. However, neither of these studies considered the time-dependent nature of variability in accessibility. Despite the increasing interest in the temporal component of accessibility, research into within and between-day variation in accessibility and its impact is limited. So far, progress concerns either the variation in accessibility within a day but without accounting for between-day variation in travel time, or the variation in accessibility over an extended time period but without differentiating by time of day. To our knowledge, there is still no accessibility study incorporating travel time reliability into a time-dependent accessibility measurement. This study will attempt to tackle this particular gap in the measurement of accessibility and provide insights into the impact of travel time reliability on accessibility. 


\subsection{Accessibility to the health care service}

Penchansky and Thomas (1981) defined access to healthcare services as "a concept representing the degree of "fit" between the clients and the system". They distinguished the following dimensions of access: availability, accessibility, accommodation, affordability and acceptability, of which accessibility is the link between the location of health supply and patients taking into account the patient's transportation resources and travel time, distance and cost. A series of published papers (Joseph and Bantock, 1982; Luo and Wang, 2003; Wang and Luo, 2005; Tanser, Gijsbertsen and Herbst, 2006 etc.) and reports (Alberti, 2006; Healthcare for London, 2008; Roberts, Blunt and Bardsley, 2014; Transport for London, 2014 etc.) confirm the importance of accessibility to the quality of the health care system. Wang and Luo (2005) and Joseph and Bantock (1982) agreed that the measurement of accessibility to health services should involve both spatial and non-spatial factors, with the former relating to the spatially uneven distribution of healthcare provision and the latter relating to socio-economic inequalities. Wang and Luo (2005) argued that the simplicity of the accessibility measurement, level of data aggregation and integrating framework play a key role on the successful integration of spatial and non-spatial factors.

\section{Development of a Dynamic Accessibility (DA) indicator}

\subsection{Introduction}

We propose a travel time reliability metric based on upper and lower percentiles of the distribution of travel time observed on a route between an origin and a destination at a specific time of day over a defined period of time. It is a non-parametric metric, which is robust against the effect of extreme values. Below, we demonstrate how to integrate this metric into an accessibility indicator.

\subsection{Travel Time Variation}

There is a range of travel time percentiles that can be used to explain day-to-day variation in travel time. Our starting point is to define travel time variation as the difference between an upper and a lower limit of observed travel time, expressed in terms of travel time percentiles (Equation 1).

$$
T T_{v a r, i j, t}=T T_{m, t}-T T_{k, t}
$$

Where $T T_{v a r, i j, t}$ is the travel time variation of the route between an origin $i$ and a destination $j$ at time $t$, $T T_{m, t}$ and $T T_{k, t}$ are the $m^{\text {th }}$ and $k^{\text {th }}$ percentile of travel times that represent the upper and the lower observed travel time at time $t$ respectively. 


\subsection{Travel Time Reliability}

Next, we define the travel time reliability of route $i j$ at time $t\left(\operatorname{TRel}_{i j, t}\right)$ as the difference between the $m^{\text {th }}$ and $k^{\text {th }}$ percentiles of travel time divided by the $m^{\text {th }}$ percentile of travel time (Equation 2). Consequently, TTRel $_{i j, t}$ is the variation in travel time (caused by day-to-day variation in demand and/or capacity) scaled by an upper limit of travel time ( $m^{\text {th }}$ percentile).

Travel Time Reliability:

$$
\operatorname{TTRel}_{i j, t}=\frac{T T_{m, t}-T T_{k, t}}{T T_{m, t}}=\frac{T T_{v a r, i j, t}}{T T_{m, t}}
$$

The Travel Time Reliability (TTRel $l_{i j, t}$ ) expresses the degree of uncertainty in the travel time on a route (or Origin-Destination (OD) pair) at a specified time of day. In essence, it expresses the percentage by which the actual travel time can vary compared to the travel time on which travellers rely to reach their destination with an $m^{\text {th }}$ percent level of certainty. TTRel takes a value between zero and one. When variation in travel time approaches zero, the value of TTRel tends to zero (very reliable travel times). As the value of TTRel increases from zero to one, the travel times become more unreliable. Due to its dimensionless formula, the comparison of dissimilar routes is possible and can be used for ranking different routes based on their travel time reliability. Figure 1 presents a theoretical graph explaining how variation in travel time is scaled to shape travel time reliability for the case of travel time distributions with the same upper travel time.

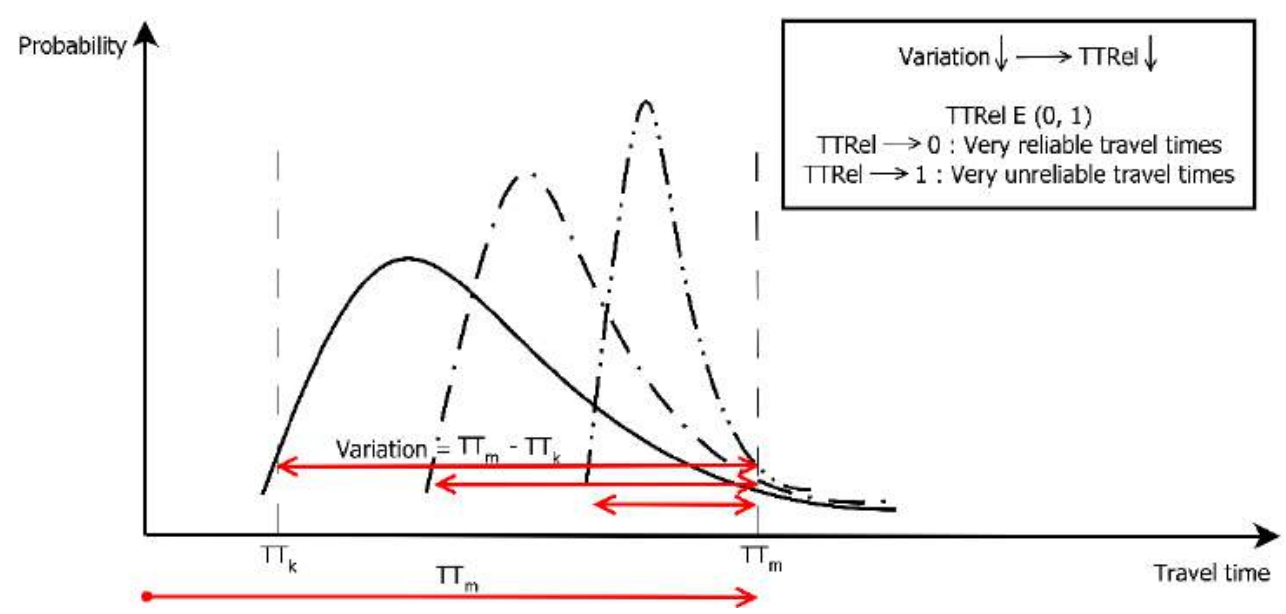

Figure 1: An example of how variation in travel time and upper travel time shape TTRel in the case of travel time distributions with the same upper travel time.

\subsection{Integration of Travel Time Reliability and Accessibility}

Our proposed approach to the integration of travel time reliability and accessibility takes the general form of a location-based accessibility indicator (Equation 3). The accessibility of origin $i$ to destination $j$ at time $t$ is computed by discounting the attractiveness of the opportunity(ies) available at this destination $\left(S_{j, t}\right)$ with a function of the travel time between the origin and destination (TT).

$$
A_{i \rightarrow j, t}=S_{j, t} \cdot f(T T)
$$

Since travel time varies within and between days, the observed travel times of OD pairs over a specified period of time can be represented in a cubic matrix of travel times as defined by Farber and Fu (2017). Although the mean or median of the observed distribution of travel time at time $t$ is typically used to compute accessibility, in the proposed approach we prefer to use the $r^{\text {th }}$ percentile of travel time, which provides the flexibility to reflect the potential impact of late arrival on travellers. Thus, higher values of $r$ can be used to reflect situations where the consequences of late arrival are high and vice versa. 
The travel time function, commonly known as the impedance (or deterrence) function was originally a power function in Hansen's specification (i.e. $1 / T T^{\alpha}$ ), but other functions (exponential decay, lognormal decay etc.) have been proposed over time. Arguments in favour of using the power-decay function have been made on the grounds of efficiency (Reggiani, Bucci and Russo, 2011). The exponent of the powerdecay function $(\alpha)$ captures the "effect of the travel time between zones" on users' behaviour (Hansen, 1959); the higher the value of the exponent is, the greater the inhibitory effect of travel time becomes. The exponent is normally treated as a fixed value for a defined population, travelling by a specified mode of transport for a particular purpose. What is missing from this specification is the inhibitory effect of travel time uncertainty, i.e. the effect of not knowing exactly what travel time to expect from one journey to the next, which has been found to affect activity participation (Bates et al., 2001; Ettema and Timmermans, 2007). To address this limitation, we propose to adjust the value of the exponent to reflect the degree of uncertainty in travel time faced by the traveller. We achieve this by raising the $r^{\text {th }}$ percentile of travel time to a linear function of the previously introduced Travel Time Reliability (TTRel).

Proposed dynamic accessibility indicator:

$$
D A_{i \rightarrow j, t}=\frac{S_{j, t}}{T T_{r, t}\left(\beta+\gamma \cdot T T R e_{i j, t}\right)}
$$

Where $D A_{i \rightarrow j, t}$ is the dynamic accessibility from zone $i$ to zone $j ; S_{j, t}$ is the size of the opportunity (supply) in zone $j ; T T_{r, t}$ is the $r^{\text {th }}$ percentile of travel times representing the time distance from $i$ to $j$; TTRel $_{i j, t}$ is the measure of travel time reliability of OD pair $i j, \beta$ and $y$ are parameters. All sizes $\left(D A_{i \rightarrow j, t}, S_{j, t}, T T_{r, t}\right.$, TTRel $_{i j, t}$ ) refer to the time $t$.

By exploring the indicator's behaviour, we can see that with invariant $S$ and $D$ values, an increase in the value of either the $T T_{r}$ or $T T R e l$ (i.e. worsening travel time reliability) leads to a decrease in accessibility. Also, the deterrence function of the proposed indicator takes the original form of Hansen's deterrence function when there is zero variation in travel time (i.e. TTRel $=0$ ).

Finally, TTRel can be said to moderate the influence of travel time $\left(T T_{r}\right)$ on accessibility. More specifically, and with reference to the index of the deterrence function, we see that:

$$
\beta+\gamma \cdot \text { TTRel }=\beta+\gamma \cdot\left(\frac{T T_{95}-T T_{5}}{T T_{r}}\right)
$$

For a fixed level of variation (i.e. $T T_{95}-T T_{5}$ ) and fixed parameters, the value of the index decreases with increasing travel time $\left(T T_{r}\right)$. Thus, whilst accessibility also decreases with increasing travel time, it does so with a decreasing rate when the level of variation is fixed. In other words, the deterrence effect of a variation of 10 minutes is more important to a traveller when journey time is 20 minutes than when journey time is 40 minutes, all other things being equal. This interaction between travel time and travel time variability is consisent with empirical evidence showing a higher tolerance and expectation of late arrival for longer journeys (Abrantes and Wardman, 2011).

\section{Case study: Accessibility of the Queen Elizabeth University Hospital under travel time uncertainty}

To illustrate the application of the proposed indicator, we used travel time data with a high temporal resolution over a 6 -month time period to demonstrate that accessibility varies significantly both spatially and temporally across the day and between days and, by not accounting for the variation in travel time, we end up with misleading results. The case study examines the accessibility of the Queen Elizabeth University Hospital (QEUH) in Glasgow, United Kingdom. 


\subsection{Background}

The QEUH is a newly built 1,677-bed hospital located to the west of Glasgow's city centre. It consists of two separate hospitals for adults and children, both of which offer major accident and emergency (A\&E) departments, as well as a full range of in-patient and day-patient services. The hospital is open for emergencies 24 hours per day, 7 days per week, and receives non-emergency patients and visitors between 7:00am and 8:30pm. The campus is among the largest in Europe with over 10,000 staff, which features a centrally located arrival square facilitating patient drop-off and access to bus and taxi services and 3,000 parking places for cars (NHS, 2018). The catchment area for this hospital depends on the particular service provided (NHS, 2018). We selected the designated catchment area for A\&E admissions. This area consists of 89 postcode sectors. Figure 2 shows the location of the QEUH, the motorway network and the surrounding catchment area including the boundaries and centroids of postcode sectors.

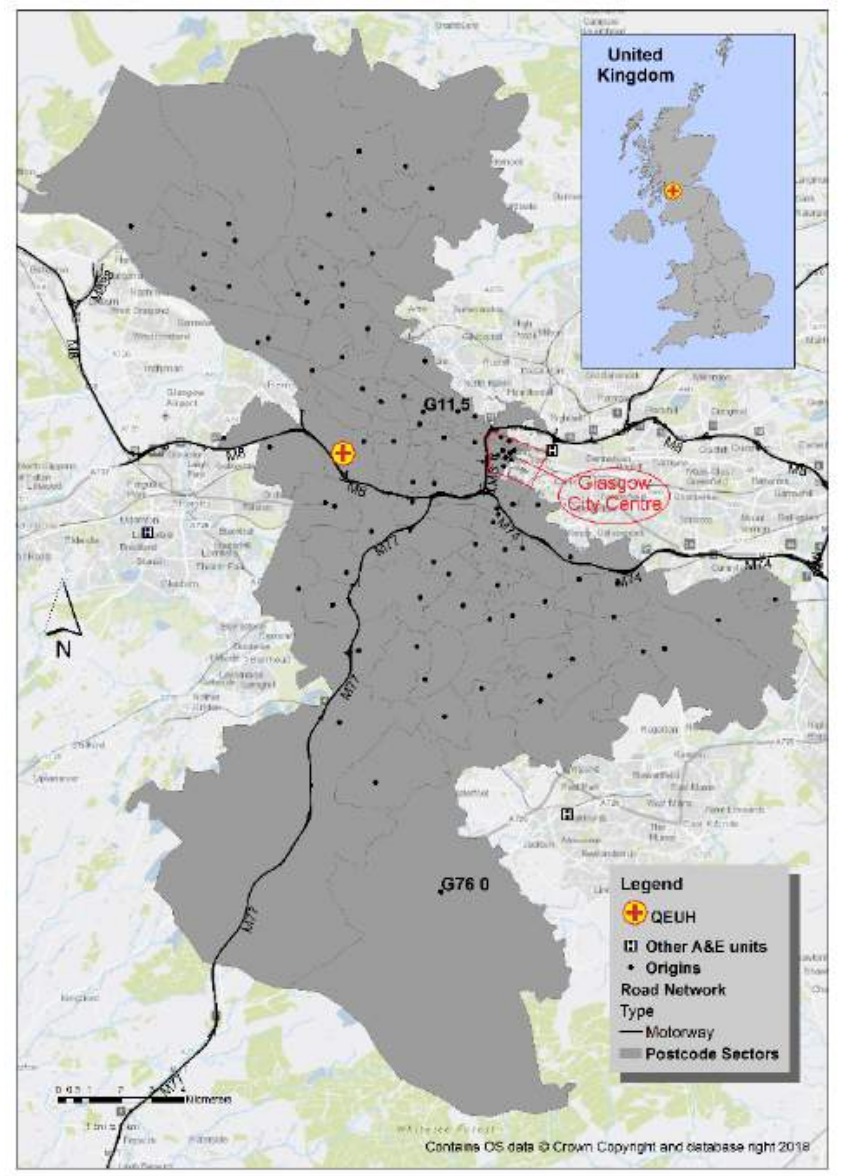

Figure 2: QEUH Catchment Area (Glasgow, UK)

\subsection{Case study focus}

This case study concerns accessibility to the QEUH by car from within the A\&E catchment area. Patients living outside the catchment area are directed to alternative major hospitals (shown in Figure 2) which are closer to them than the QEUH. Although the main target group was A\&E patients, our analysis applies also to in-patients, out-patients, visitors and employees travelling by car from origins within this catchment area. It is worth noting that the consequences of late (and early) arrival are not the same for each subgroup; patients and doctors face significant consequences if they do not arrive on time, while the consequences of late arrival for visitors and paraclinical staff are less so. In addition, although A\&E patients do not have the luxury of adopting safety margins for avoiding late arrival consequences compared to other subgroups, travel time unreliability is still crucial for their timely access to the hospital. 


\subsection{Methodology}

\subsubsection{Data Collection}

Travel times were collected by repeatedly querying the Google Distance Matrix API (GDMA) (Google Distance Matrix API, 2018). Google produces travel time predictions by tracking Android hand-sets through time and space and processing this data using undisclosed algorithms. Since 2010, only a few studies reported the use of data originating from Google's applications (Wang and Xu, 2011; Socharoentum and Karimi, 2015), although none has verified the accuracy of the reported data which depends on the number of Android hand-sets with location services switched on using a road network, the accuracy of tracking technology and the algorithms used to process the raw data. We must therefore treat with caution the accuracy of the travel time data used in this study, and the variation in this accuracy across the network and over time.

Data collection was designed to achieve an efficient balance between the temporal and spatial resolution of travel times from selected origins within the catchment area to the QEUH, whilst staying within the free-use limits of GDMA. Each origin was the centroid of one randomly selected postcode unit within each postcode sector, which gave a total of 89 origins. Travel time data was collected at 15minute intervals between 7:00 am and 9:00 pm on weekdays from November 2016 to May 2017 excluding the Christmas holiday period and weekends.

\subsubsection{Measurement of Travel Time Reliability}

The $T T_{v a r, i j, t}$ (Equation 1) and $T T R e l_{i j, t}$ (Equation 2) were calculated for each of the 56 distinct time points, $t$, within the chosen time interval (7:00 am to 9:00 pm). To illustrate the use of these metrics, we chose the $95^{\text {th }}$ and the $5^{\text {th }}$ percentile of travel times as the upper and the lower observed travel times respectively. Thus, Equations 1 and 2 can be stated as:

$$
\begin{aligned}
& \operatorname{TTvar}_{i j, t}=T T_{95, t}-T T_{5, t} \\
& \operatorname{TTRel}_{i j, t}=\frac{T T_{95, t}-T T_{5, t}}{T T_{95, t}}
\end{aligned}
$$

\subsubsection{Computation of Accessibility}

Two accessibility indicators were computed based on Equation 4 . For both indicators, the $95^{\text {th }}$ percentile of travel times $\left(T T_{95, t}\right)$ was used in the deterrence function to reflect the relatively high penalty paid by patients and staff for late arrival at the hospital leading to the adoption of a risk averse attitude to travel time whilst excluding travel times at the upper end of the distribution (see Section 5.2 below for example of the impact of concurrent incidents on travel time).

The first indicator formed a time-dependent accessibility indicator (TA) in which the exponent in the power-decay deterrence function was equal to one (i.e. $\beta=1$ and $\gamma=0$ ). Thus, no account was made for day-to-day variation in travel time. The second indicator accounted for between-day dynamic accessibility (DA) by including TTRel in the power decay function $(\beta=1$ and $\gamma=1)$ which yielded a higher value of exponent, and thus a lower value of accessibility, except for the case where TTRel equals zero. Comparison between the two measurements is straightforward and the difference between them reflects the reduction in accessibility resulting from day-to-day variability. Since we examined only one destination, the supply $S_{j}$ was taken to be equal to one for the sake of simplicity. Whilst $S_{j}$ was invariant over time in this illustration, in other studies this could allowed to vary over the course of the day. The two accessibility indicators were formed as follows: 
1. Time-dependent accessibility (TA):

$$
T A_{i \rightarrow j, t}=\frac{1}{T T_{95, t}}
$$

2. Dynamic accessibility (DA):

$$
D A_{i \rightarrow j, t}=\frac{1}{T T_{95, t}\left(1+T T R e l_{i j, t}\right)}
$$

\section{Results}

\subsection{Overview}

A total of 618,105 travel time queries to the GDMA were carried out over the study period. On 533 occasions, the GDMA returned a null response $(0.086 \%$ of the overall queries). The missing data was randomly distributed across OD pairs and was thus ignored in the analysis, as there was no significant impact on the final results.

\subsection{Variation in Travel Times}

To help visualise the temporal variation in travel time distribution, we constructed Time-Dependent MultiHistograms (TDMH) for each zone. Each row in the TDMH shows the distribution of travel times for a 15-minute period between 7:00 am and 9:00 pm. Figures 3 and 4 present these visualisations for two selected zones (Postcode Sectors G76 0 and G11 5 (located to the west of the city centre; see Figure 2 for location)). The vertical red line in each figure shows the median observed travel time. Whereas Postcode Sector G76 0 experienced a larger travel time variation in the morning peak period compared to the evening peak period, the reverse was true for Postcode Sector G11 5. Inspection of the travel time distributions of the other zones in the study area (see Supplementary Material) revealed notable spatial as well as temporal variations in travel time.

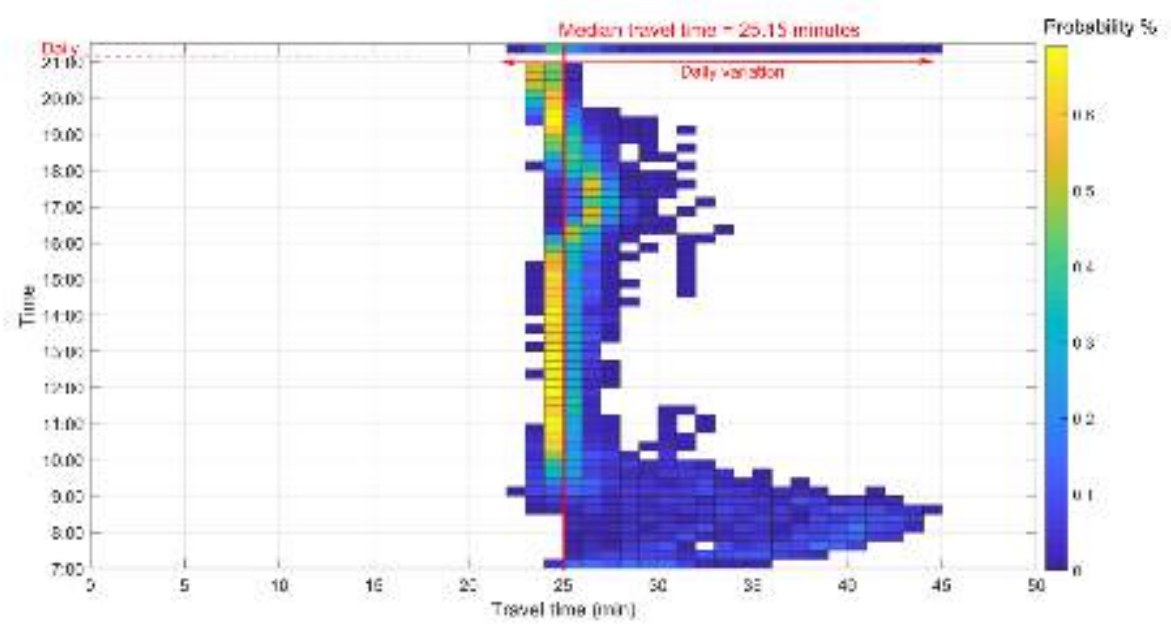

Figure 3: Time-Dependent Multi-Histogram (TDMH) of travel times - Postcode Sector: G76 0 


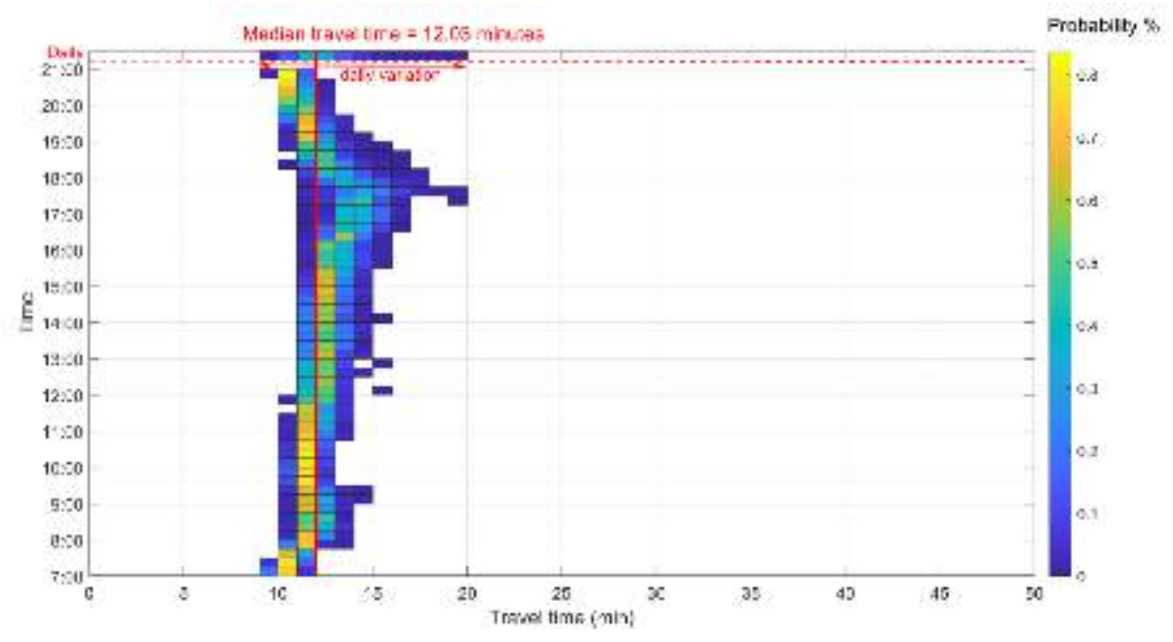

Figure 4: Time-Dependent Multi-Histogram (TDMH) of travel times - Postcode Sector: G11 5

\subsection{Travel Time Reliability}

Figures 5, 6 and 7 show observed Travel Time Reliability (TTRel) for each zone at 8:30 am, 11:00 am and 5:30 pm respectively. (See Supplementary Material for a visualisation of TTRel throughout the day). Zones in dark shading exhibited very low reliability i.e. a day-to-day variation in travel time greater than $35 \%$ relative to the $95^{\text {th }}$ travel time percentile. At 8:30 am, which was selected to represent the morning peak period, a large number of zones experienced travel time unreliability. At 5:30 pm (representing the evening peak period), the zones that suffered the most unreliability lie along an axis from the northwest to southeast. It should be noted that the zones that were most affected by unreliability in the morning peak period are not the same as those which experienced high levels of unreliability in the evening peak period. At 11:00 am, only a few zones exhibited very low travel time reliability; this highlights the effect of travel demand (and redundant capacity) on reliability. Zones close to the QEUH returned high values of TTRel - however it must be recalled that TTRel is a relative measure of reliability and that these zones exhibited shorter absolute travel times in comparison with other zones.

\subsection{Dynamic Accessibility (DA)}

Figures 8, 9 and 10 show the DA to the QEUH at 8:30 am, 11:00 am and 5:30 pm respectively. (See Supplementary Material for a visualisation of DA throughout the day). Zones in dark shading experienced low accessibility levels which can be explained by relatively high levels of travel deterrence which is shaped by longer travel times and/or higher travel time unreliability. Comparison of these three figures shows that the impacts of unreliability are more widespread in the morning peak period than in the evening peak period.

The impact of travel time reliability on accessibility can be quantified by subtracting TA from DA for each zone at each distinct point in time. Using the same scale as above, Figures 11, 12 and 13 depict the difference between TA and DA at 8:30 am, 11:00 am and 5:30 pm across the study area respectively. (See Supplementary Material for a visualisation of the difference between TA and DA throughout the day). The results mirror those of TTRel - in the morning peak period, significant impacts were found in zones located on two axes within the catchment area; north to south and south-east to north-west, while in the evening peak period, significant impacts were found on the south-east to north-west axis. 


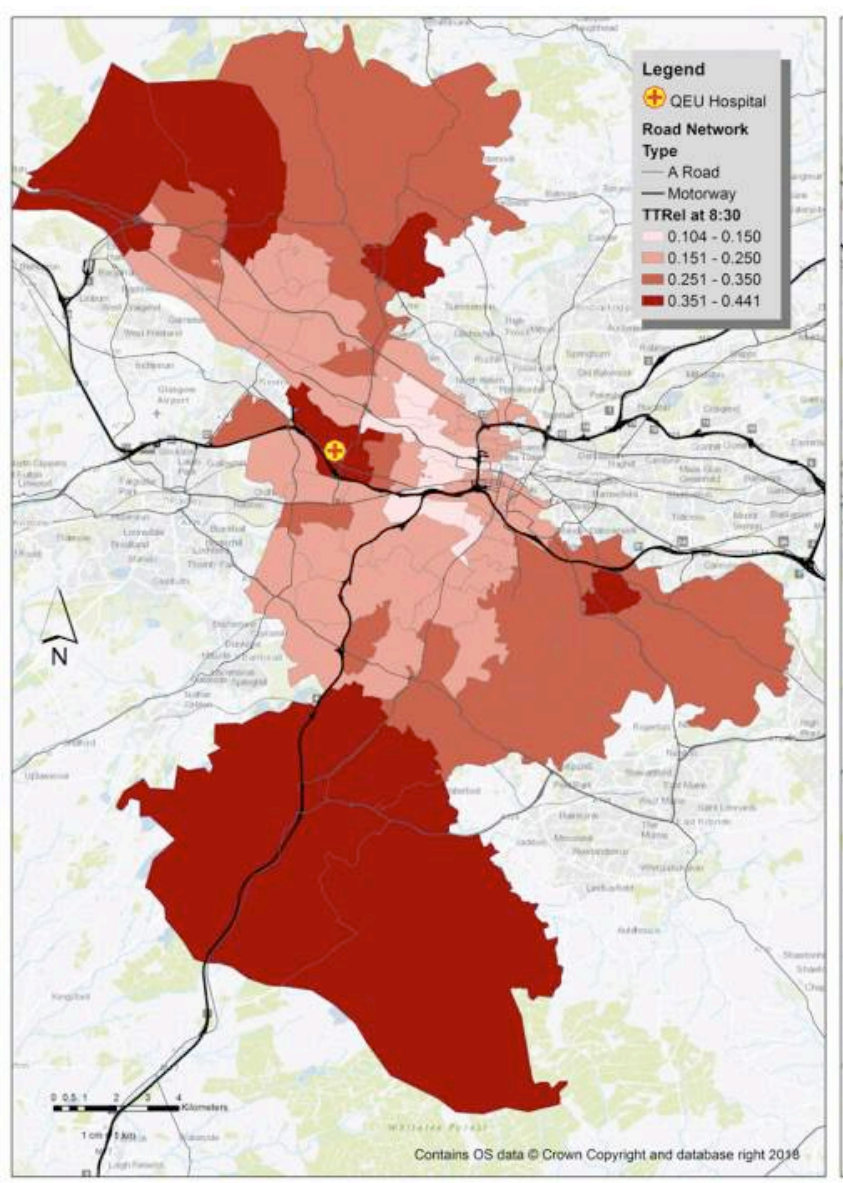

Figure 5: TTRel at 8:30 am

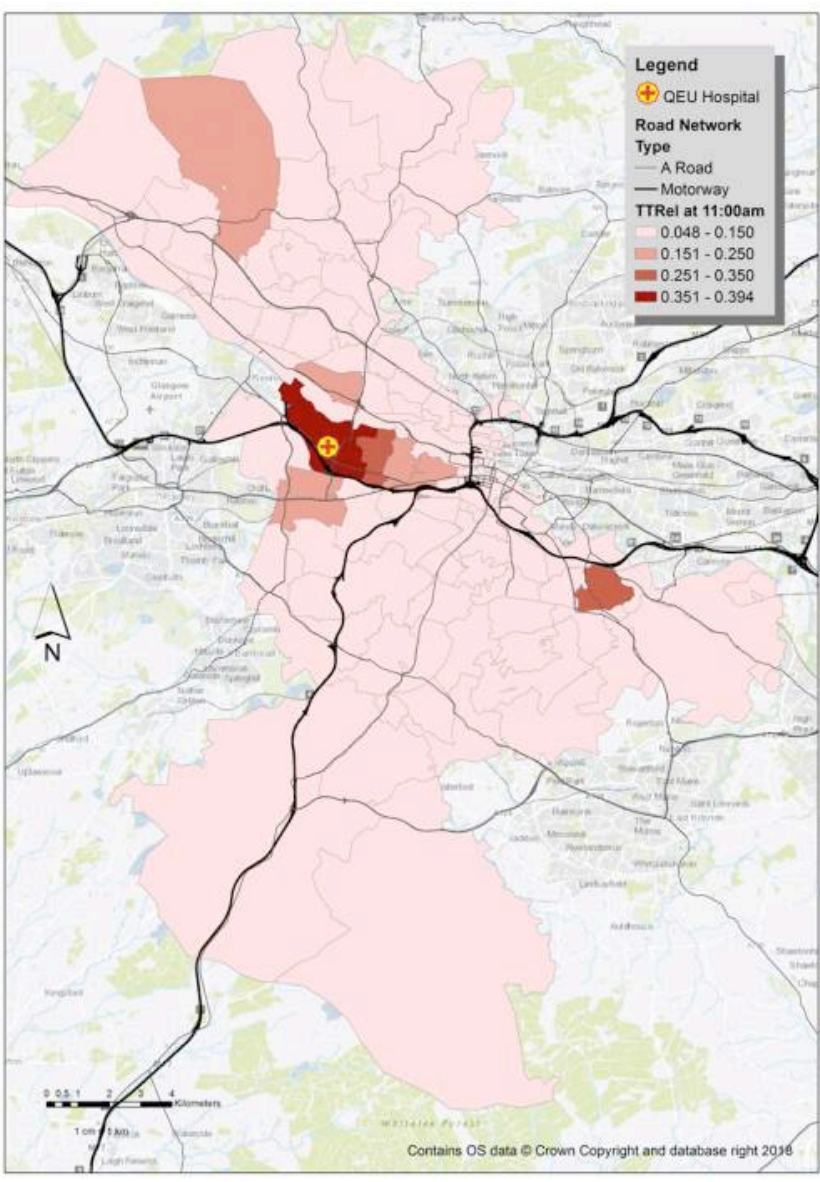

Figure 6: TTRel at 11:00 am

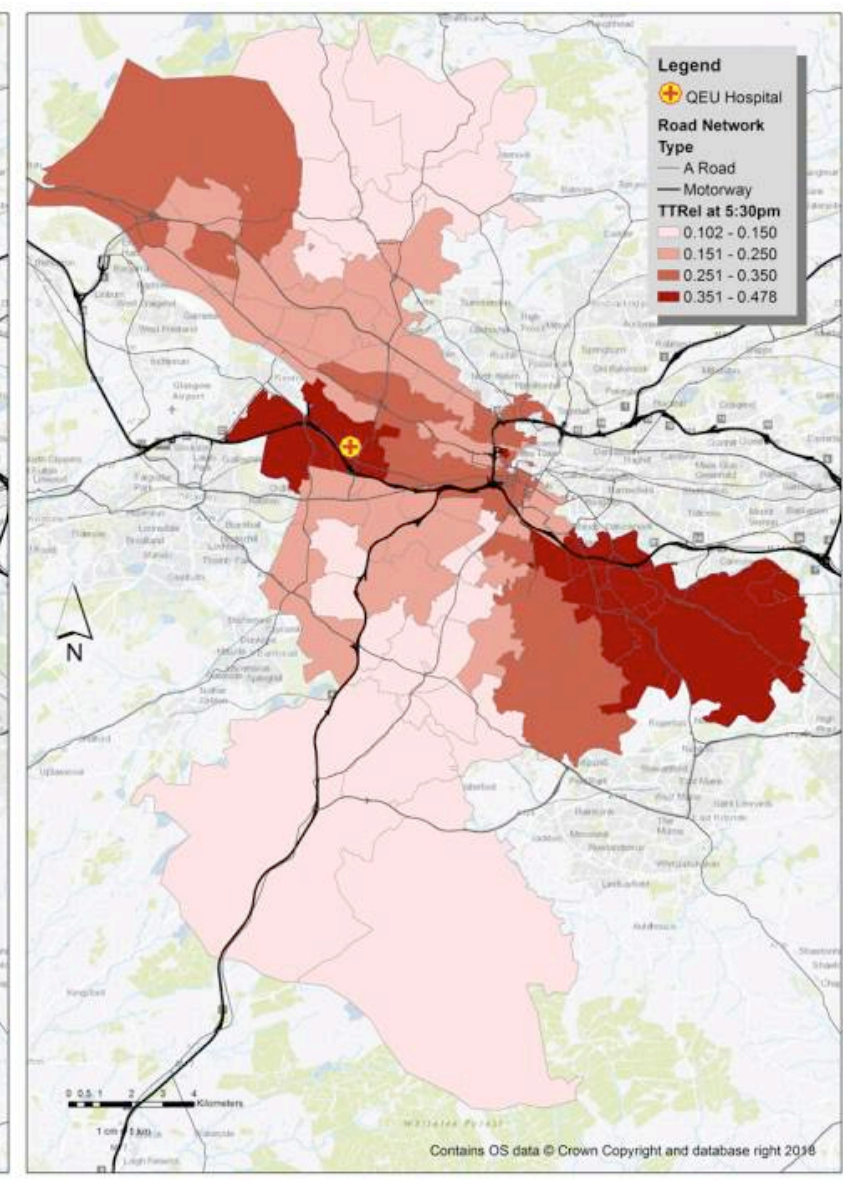

Figure 7: TTRel at 5:30 pm 


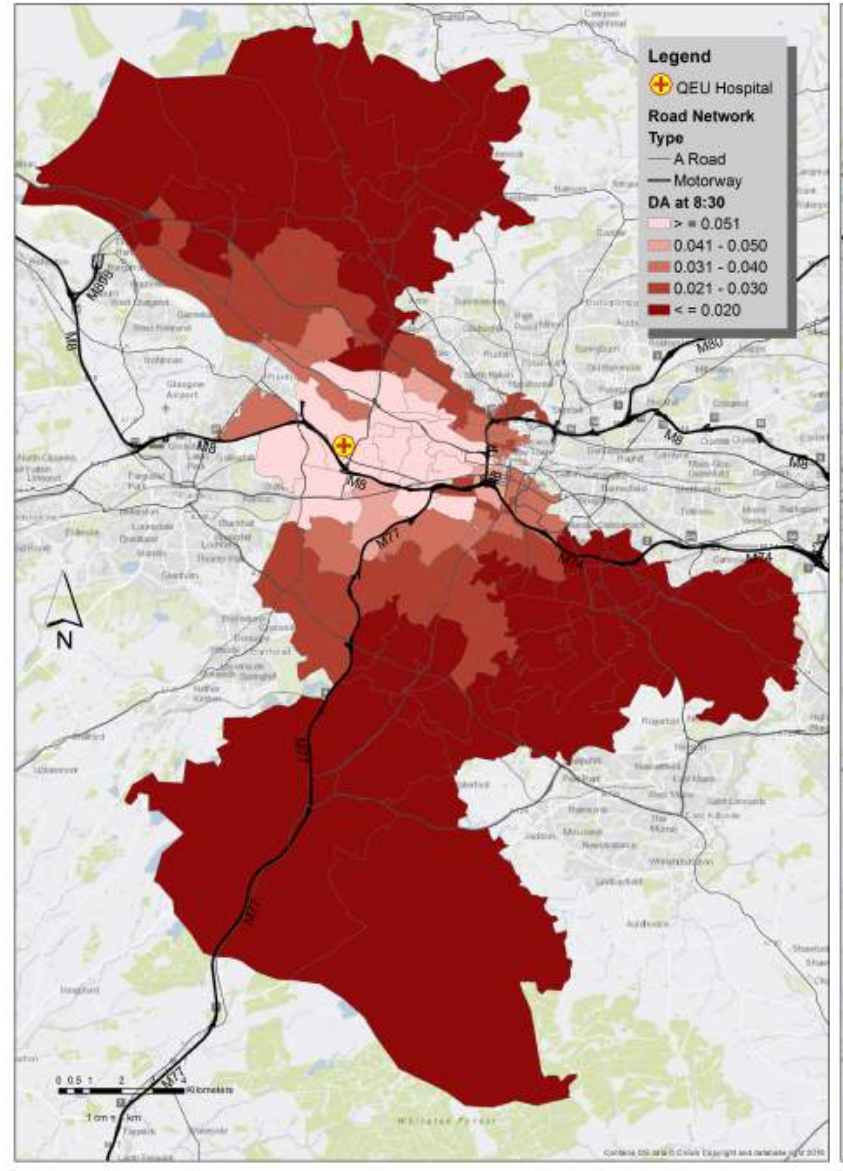

Figure 8: DA at 8:30 am

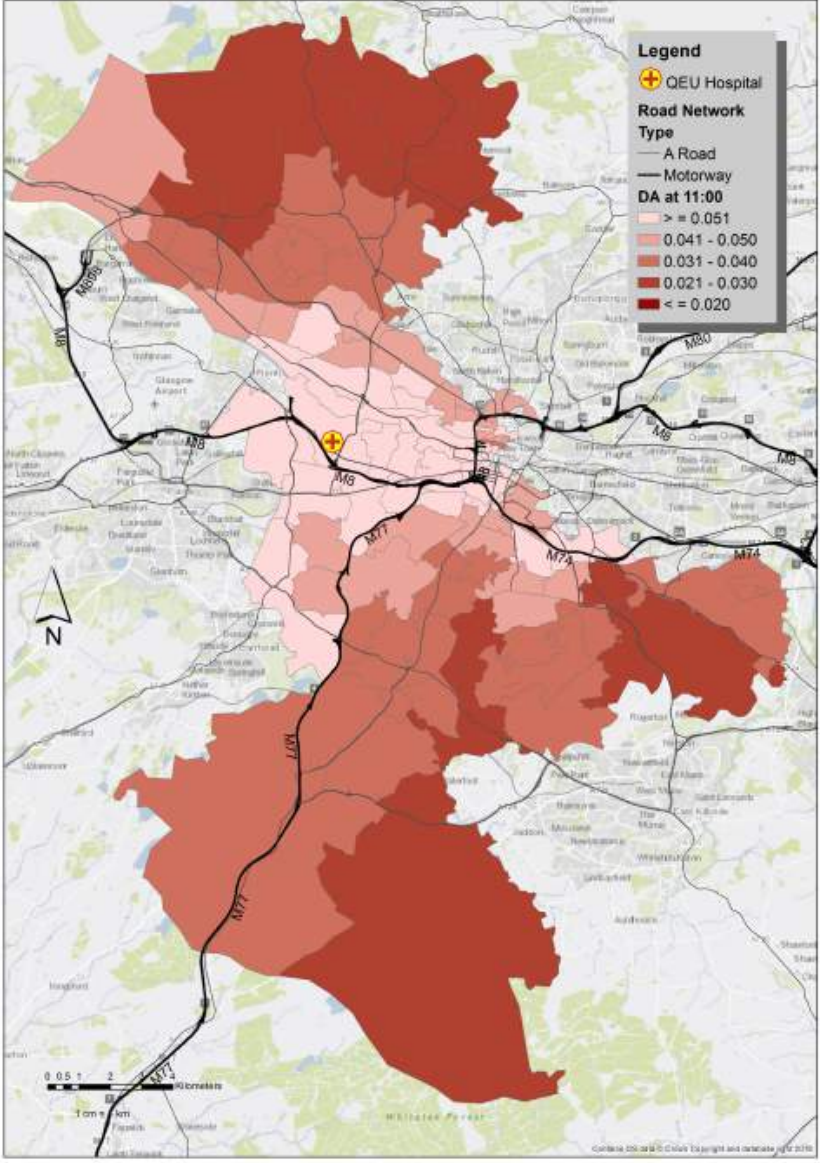

Figure 9: $D A$ at 11:00 am

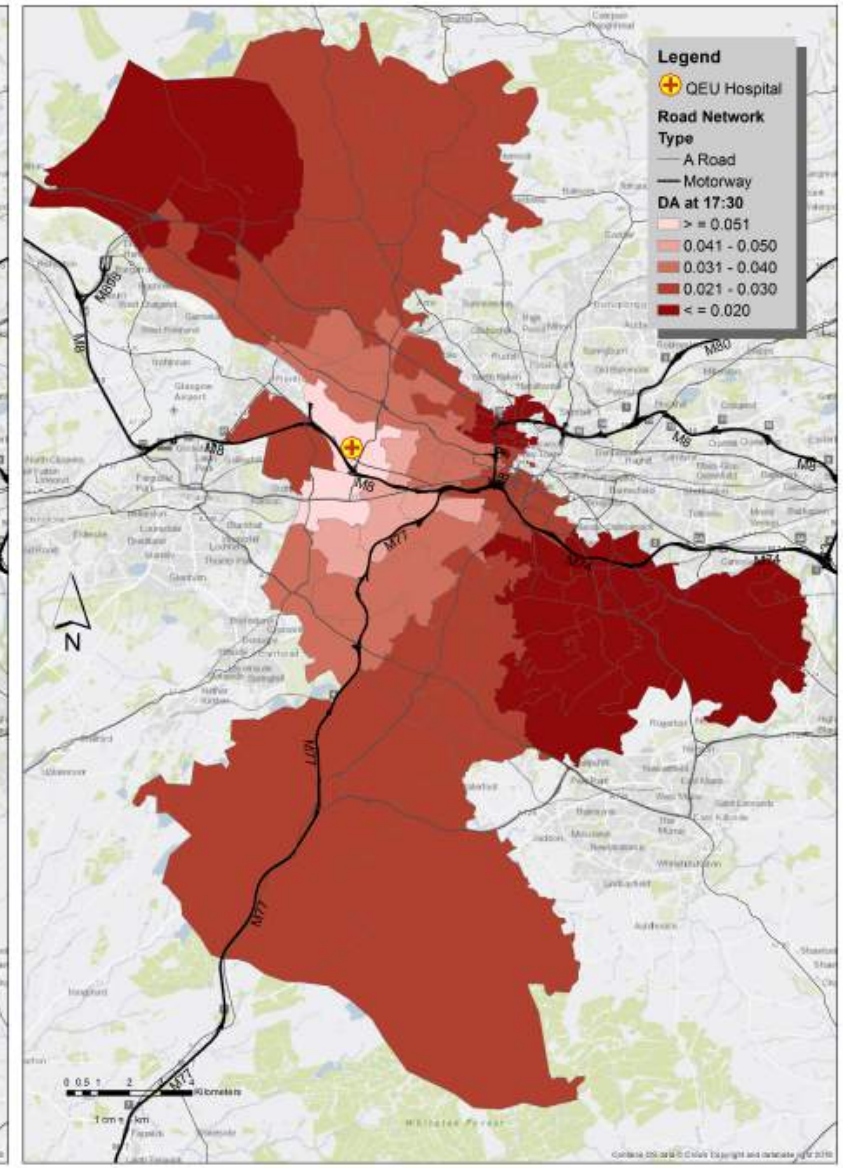

Figure 10: $D A$ at $5: 30 \mathrm{pm}$ 


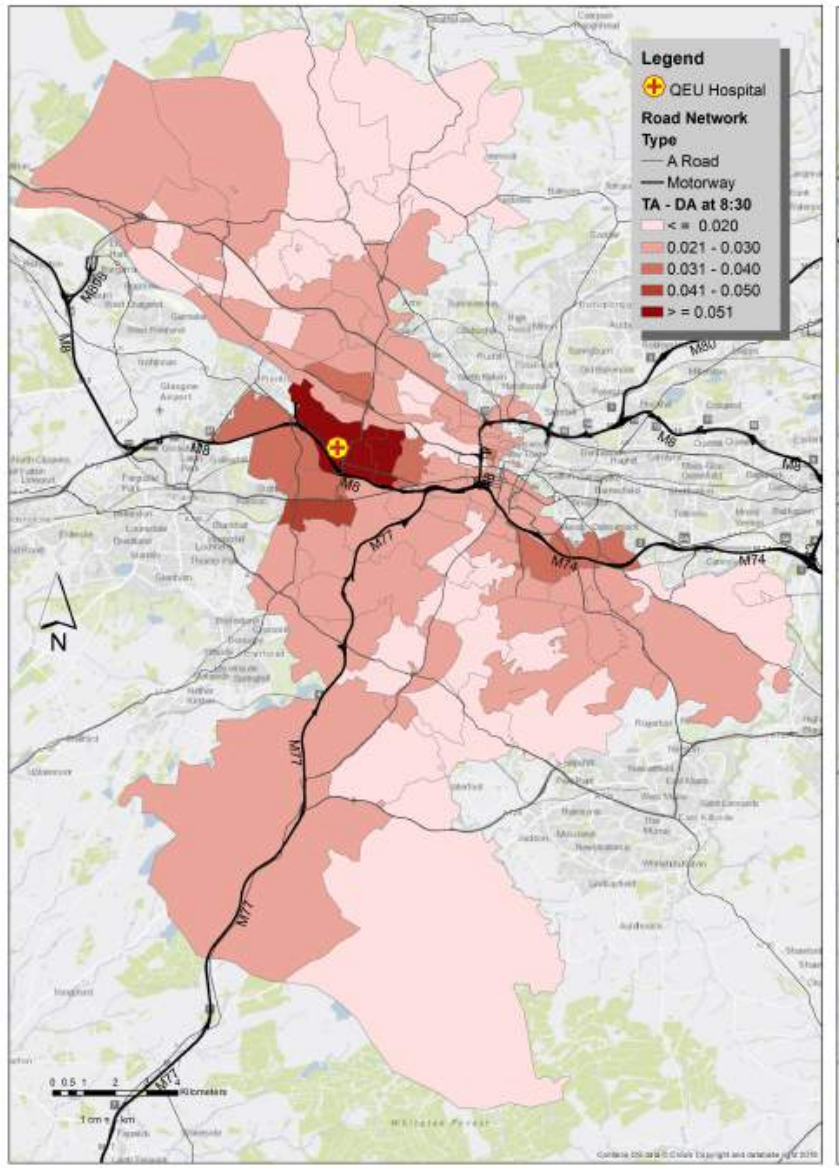

Figure 11: Difference between TA and DA at 8:30 am

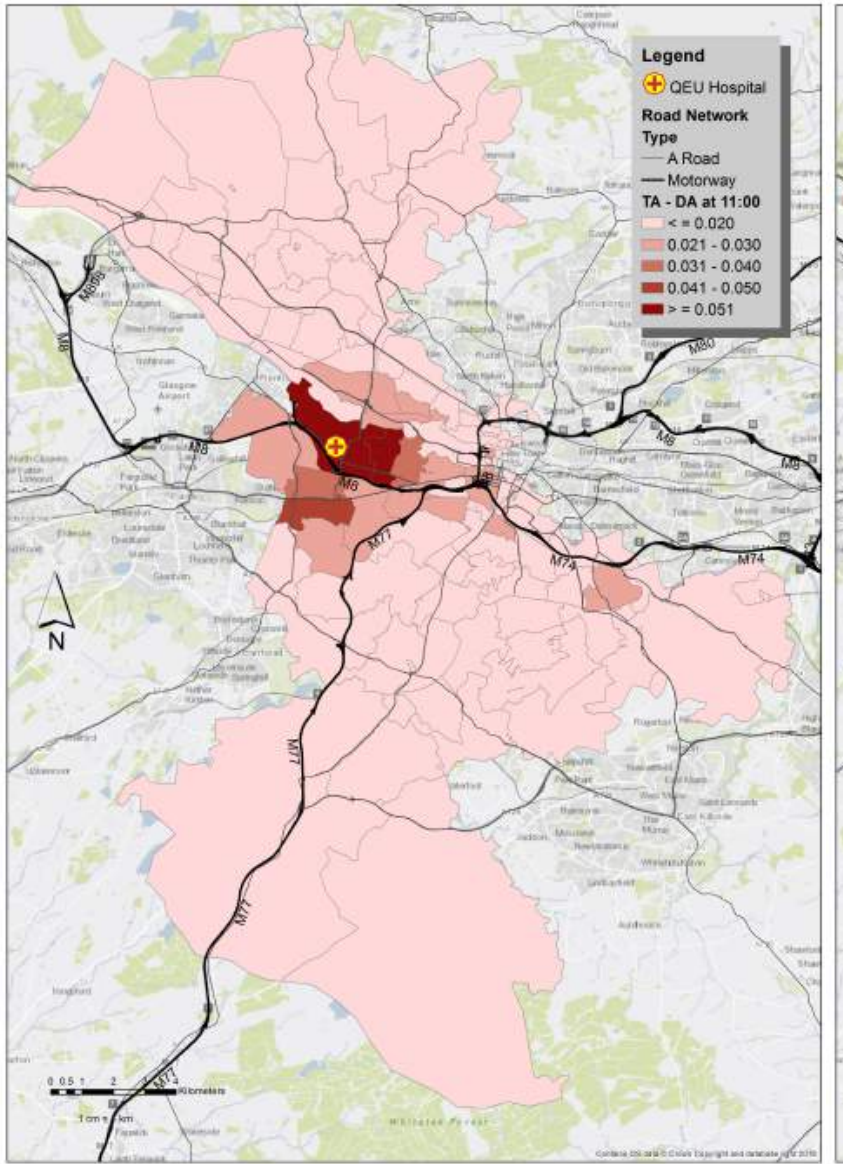

Figure 12: Difference between TA and DA at 11:00 am

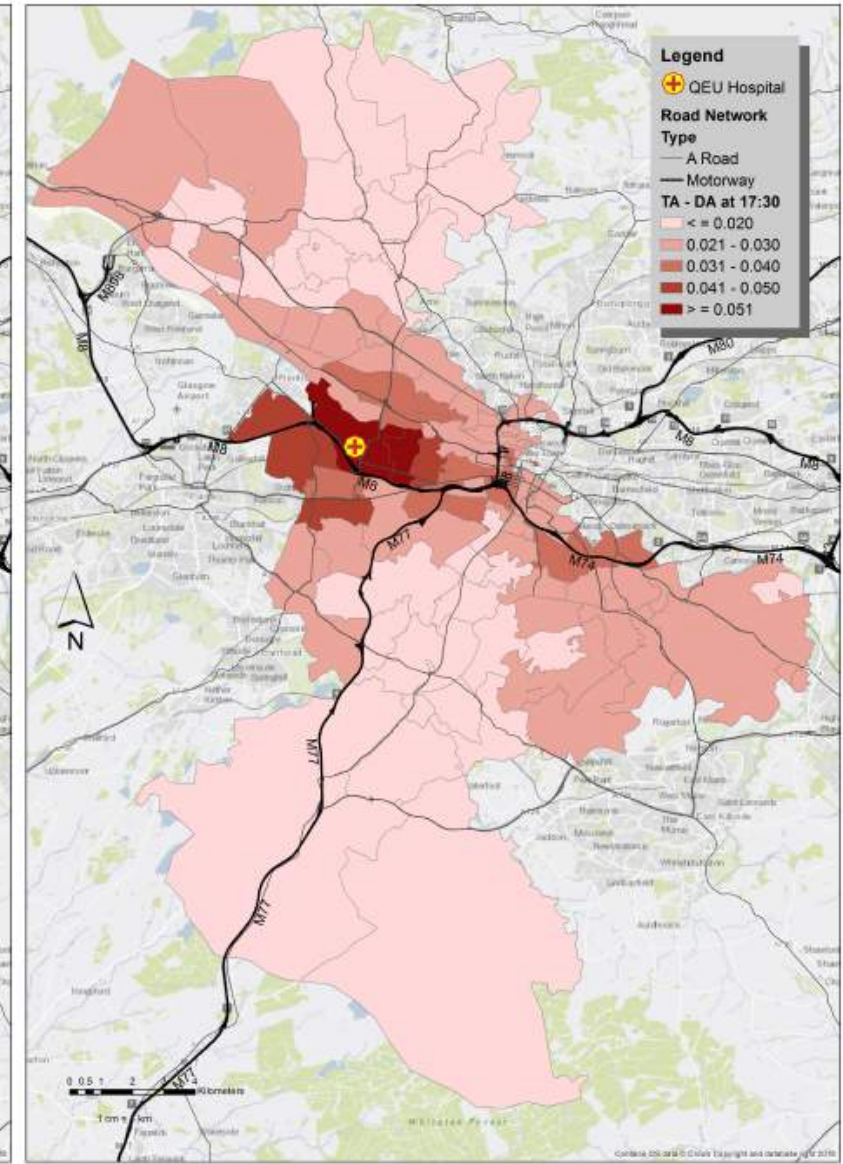

Figure 13: Difference between TA and DA at 5:30 pm 


\section{Conclusions and Discussion}

In this paper, we extended a commonly-used accessibility indicator to include day-to-day variability in travel times. We argued that it is important to incorporate the degree of travel time unreliability into the measurement of accessibility since we know that travellers value journey time reliability (Bates et al., 2001 and de Jong and Bliemer, 2015) and that unreliability is a pervasive feature of many current transport networks (OECD and ITF, 2010 and de Jong and Bliemer, 2015). We also considered it important to understand how day-to-day accessibility varies throughout the day since many important accessibility needs take place outside of rush hours. Furthermore, the ready-availability of published travel time data derived from GPS-enabled mobile phones gives transport planners and network managers the opportunity to analyse the spatial, temporal and socio-economic impacts of travel time reliability on accessibility.

We applied the proposed indicator to examine dynamic weekday accessibility by car to a newly-opened major hospital in Glasgow, UK. Firstly, our results show systematic differences in the relative impact of morning and evening peak periods on travel time to the hospital across the study area and that the extent of day-to-day reliability of travel time (as measured by TTRel) varies both temporally and spatially. In practical terms, the chance of a traveller being late (or early) is dependent on both time of day and origin location. This underscores the importance of including travel time reliability in addition to a single, representative value of travel time (such as the median) in the measurement of accessibility. Secondly, we found that DA generally increased with distance from the hospital and that this effect was most pronounced in the morning peak period. When we mapped the difference between a standard accessibility indicator (TA) and DA, we found that zones located close to the motorway network experienced relatively high levels of accessibility loss due to higher travel time variability, which suggests that the route corridors connecting these zones with the hospital are operationally sensitive to day-to-day fluctuations in flow or capacity or both, although we cannot discount the possibility that our results are influenced by the way that Google processes its data. Cui and Levinson (2018) found a similar relationship between motorway dependency and vulnerability to travel time variability in Minneapolis - St Paul, Minnesota region, albeit using a different technique to measure accessibility.

The approach presented in this paper links two recent trends in accessibility studies (those, which addressed within-day variation in accessibility, and those, which addressed the impact of day-to-day variation in travel time on accessibility). Unlike Cui and Levinson (2018), who constructed origindestination travel times using individual link speed percentiles $\left(10^{\text {th }}, 50^{\text {th }}\right.$ and $\left.90^{\text {th }}\right)$ to calculate 'best', 'middling' and 'worst' case accessibilities for a typical day, we used real-time travel time estimates in our analysis to measure accessibility which we believe provides a more realistic representation of actual network performance and allows us to examine how reliability affects accessibility throughout the day.

We chose to use a power deterrence function in our model and, with the availability of a suitable travel behaviour dataset, the model parameters can be estimated using non-linear regression. The approach could be easily adapted to other deterrence functions, including an exponential deterrence function of the form $\exp (\beta T T+\gamma T T R e l)$ which is frequently used in accessibility studies and is linked with random utility theory. Furthermore, with the incorporation of travel time variability, person and individual-level utility-based accessibility indicators would potentially offer insights into the impact of travel time unreliability since such indicators would reflect spatial/temporal constraints in activity participation and choice behaviour respectively. However, the individual-level data requirements in either case would be significantly more burdensome and were beyond the scope of this project. Finally, our accessibility indicator assumes that the deterrence effect of travel time variation declines with increasing travel time. This assumption stands in contrast to numerous travel time reliability studies which assume that (dis)utility is equal to the weighted sum of expected travel time and travel time variation (Carrion and Levinson, 2012) - in which case the deterrence effect of a fixed travel time variation would be 
independent of travel time. This raises interesting questions about how time is valued and, more specifically, the degree of interaction between travel time and travel time variability.

One limitation of our study is that the method used by Google to process raw data into the travel time estimations extracted from the GDMA is not published nor was the data validated against another source of data. A second limitation is that the extracted data relates to the estimated shortest (in time) path between an origin and the hospital that existed at a specified point in time. However, as a result of changing traffic conditions, the shortest path did not necessarily follow the same route throughout the survey period. Travel times on alternative routes to the shortest path were not collected. As a result, there may have been one or more routes, which would have delivered longer travel times than the shortest path for some or indeed all of the study period, but with lower overall levels of variability/reliability than that computed in this study. How travellers evaluate different route options and the effect this evaluation has on the perception of accessibility (Ettema and Timmermans, 2007; Miller, 2010; Kwan, 2010) was not explored in this study. A third limitation is that the time taken to park and access the hospital is itself a source of variability/uncertainty which we did not take into account in this study because of a lack of data. We acknowledge that this component of travel time will depend on a variety of factors including the type and availability of parking and the quality of local signage as well as whether the journey is undertaken as driver alone or as a car passenger. Furthermore, we recognise that it would be essential to include parking in access time in future studies involving other modes of transport in order to give a fair comparison. A fourth limitation is that the spatial resolution is lower in the larger, sparsely populated zones located towards the edge of the catchment area. Analysis at a higher spatial resolution may reveal pockets of relatively high or low accessibility compared to the parent zone.

The aim of the study was to develop an approach to integrate travel time reliability into the measurement of accessibility. To illustrate the application of the proposed indicator, we adopted a simplified version of the deterrence function without calibrating the deterrence parameters. Future work should seek to estimate parameter values using actual or stated preferences of travellers. Moreover, we chose to focus on the accessibility of a single hospital since in most cases this would be the only relevant destination for travellers as patients, visitors or employees. In some cases, travellers will have a choice of which hospital to attend in which case our approach would remain valid if accessibility was summed over multiple destinations in the normal fashion. Finally, it should be noted that the study area selected for this study does not reflect the wider catchment area served by the QEUH for more advanced or specialised treatments.

Our approach gives hospital managers, working with transport officials, insight into those zones which experience poor accessibility to hospital resulting from the combination of travel time and travel time unreliability either at specific times of day or potentially by aggregating DA across the day. Resources could then be targeted on improving the road network connecting vulnerable zones or by supporting alternative modes, and hence populations at risk, to achieve more equitable access to the hospital. The accessibility indicator could also be used to plan or adjust catchment area boundaries for hospitals or in studies examining the most suitable location of a new hospital. Furthermore, understanding how travel time reliability varies throughout the day from different parts of a transport network could be used by hospital managers to develop strategies to minimise costs due to missed patient appointments and late arrival of staff. For example, the timing of clinics etc. or the scheduling of individual appointments could seek to avoid periods of poor accessibility. Future research should explore the relationship between accessibility, late arrivals and missed appointments, with the results contributing to a better understanding of how accessibility influences operational efficiency. Furthermore, appointment information provided to patients could highlight the level of reliability associated with travel from their home to the hospital at the relevant time of day and, where appropriate, to advise them to check travel times in advance or to depart early, particularly if the appointment coincides with a period of high parking demand. 
The emergence of "big" mobility data is a lure for researchers providing them with the opportunity to study dynamic phenomena without having to undertake superlative difficulties in data collection. At this stage, there is plenty of space for research on the temporal component of accessibility. It is important for future work to shed more light on the impact of travel time reliability on accessibility, social equity and specific vulnerable sub-groups (e.g. old, deprived, low car-ownership), and the gap between car and public transport accessibility, which is often measured disadvantageously compared to car accessibility without taking into account travel time reliability.

\section{References}

Abrantes, P. A. L. and Wardman, M. R. (2011) 'Meta-analysis of UK values of travel time: An update', Transportation Research Part A: Policy and Practice, 45(1), pp. 1-17. doi: 10.1016/j.tra.2010.08.003.

Alberti, S. G. (2006) Emergency Access - Clinical Case for Change. Available at: http://www.nhshistory.net/emergencycare.pdf (Accessed: 9 August 2017).

Alvarez, P. and Hadi, M. (2012) 'Time-Variant Travel Time Distributions and Reliability Metrics and Their Utility in Reliability Assessments', Transportation Research Record: Journal of the Transportation Research Board, 2315(1), pp. 81-88. doi: 10.3141/2315-09.

Bates, J. et al. (2001) 'The valuation of reliability for personal travel', Transportation Research Part E: Logistics and Transportation Review, 37(2-3), pp. 191-229. doi: 10.1016/S1366-5545(00)00011-9.

Bell, M. G. H. and lida, Y. (1997) Transportation network analysis. Chichester, UK: John Wiley \& Sons, Ltd. doi: 10.1002/9781118903032.

Boisjoly, G. and El-Geneidy, A. (2016) 'Daily fluctuations in transit and job availability: A comparative assessment of time-sensitive accessibility measures', Journal of Transport Geography. Pergamon, 52, pp. 73-81. doi: 10.1016/J.JTRANGEO.2016.03.004.

Carrion, C. and Levinson, D. (2012) 'Value of travel time reliability: A review of current evidence', Transportation Research Part A: Policy and Practice. Pergamon, 46(4), pp. 720-741. doi: 10.1016/J.TRA.2012.01.003.

Chen, A. et al. (1999) 'A capacity related reliability for transportation networks', Journal of Advanced Transportation. Wiley-Blackwell, 33(2), pp. 183-200. doi: 10.1002/atr.5670330207.

Chen, B. Y. et al. (2017) 'Measuring place-based accessibility under travel time uncertainty', International Journal of Geographical Information Science, 31(4), pp. 783-804. doi: 10.1080/13658816.2016.1238919.

Cui, M. and Levinson, D. (2018) 'Accessibility and the Ring of Unreliability', Transportmetrica A: Transport Science. Taylor \& Francis, 14(1-2), pp. 4-21. doi: 10.1080/23249935.2016.1258441.

Ettema, D. and Timmermans, H. (2006) 'Costs of travel time uncertainty and benefits of travel time information: Conceptual model and numerical examples', Transportation Research Part C: Emerging Technologies. Pergamon, 14(5), pp. 335-350. doi: 10.1016/J.TRC.2006.09.001.

Ettema, D. and Timmermans, H. (2007) 'Space-Time Accessibility Under Conditions of Uncertain Travel Times: Theory and Numerical Simulations', Geographical Analysis, 39(2), pp. 217-240. doi: 10.1111/j.1538-4632.2007.00702.x.

Farber, S. and Fu, L. (2017) 'Dynamic public transit accessibility using travel time cubes: Comparing the effects of infrastructure (dis)investments over time', Computers, Environment and Urban Systems. Pergamon, 62, pp. 30-40. doi: 10.1016/J.COMPENVURBSYS.2016.10.005.

Farber, S., Morang, M. Z. and Widener, M. J. (2014) 'Temporal variability in transit-based accessibility to supermarkets', Applied Geography. Pergamon, 53, pp. 149-159. doi: 10.1016/J.APGEOG.2014.06.012.

Feng, T., Rasouli, S. and Timmermans, H. J. P. (2013) 'Equity impact of incorporating uncertainty in 
travel times in measurment of accessibility', in 13th World Conference on Transportation Research (WCTR). Rio de Janeiro, p. 1-10(online). Available at: http://www.wctrs.leeds.ac.uk/wp/wpcontent/uploads/abstracts/rio/general/3649.pdf (Accessed: 20 July 2017).

Fransen, K. et al. (2015) 'Identifying public transport gaps using time-dependent accessibility levels', Journal of Transport Geography. doi: 10.1016/j.jtrangeo.2015.09.008.

Geurs, K. T., De Montis, A. and Reggiani, A. (2015) 'Recent advances and applications in accessibility modelling', Computers, Environment and Urban Systems. Pergamon, 49, pp. 82-85. doi: 10.1016/J.COMPENVURBSYS.2014.09.003.

Geurs, K. T. and van Wee, B. (2004) 'Accessibility evaluation of land-use and transport strategies: Review and research directions', Journal of Transport Geography, 12(2), pp. 127-140. doi: 10.1016/j.jtrangeo.2003.10.005.

Google Distance Matrix API (2018) Developer Guide | Distance Matrix API | Google Maps Platform. Available at: https://developers.google.com/maps/documentation/distance-matrix/intro (Accessed: 26 November 2018).

Hall, R. W. (1983) 'Travel outcome and performance: The effect of uncertainty on accessibility', Transportation Research Part B: Methodological. Pergamon, 17(4), pp. 275-290. doi: 10.1016/01912615(83)90046-2.

Hansen, W. G. (1959) 'How Accessibility Shapes Land Use', Journal of the American Institute of Planners. Taylor \& Francis Group , 25(2), pp. 73-76. doi: 10.1080/01944365908978307.

Healthcare for London (2008) Travel Times and Ambulance coverage analysis for Stroke and Trauma. Available at: http://www.londonhp.nhs.uk/wp-content/uploads/2011/03/Travel-TimesAmbulance-Coverage-Analysis.pdf (Accessed: 9 August 2017).

Herman, R. and Lam, T. (1974) 'Trip time characteristics of journeys to and from work', Transportation and traffic theory, 6, pp. 57-86. Available at: https://trid.trb.org/view.aspx?id=40316 (Accessed: 2 July 2018).

lida, Y. (1999) 'Basic concepts and future directions of road network reliability analysis', Journal of Advanced Transportation. John Wiley \& Sons Ltd, 33(2), pp. 125-134. doi: 10.1002/atr.5670330203.

de Jong, G. C. and Bliemer, M. C. J. (2015) 'On including travel time reliability of road traffic in appraisal', Transportation Research Part A: Policy and Practice. Pergamon, 73, pp. 80-95. doi: 10.1016/J.TRA.2015.01.006.

Joseph, A. E. and Bantock, P. R. (1982) 'Measuring potential physical accessibility to general practitioners in rural areas: A method and case study', Social Science \& Medicine, 16(1), pp. 85-90. doi: 10.1016/0277-9536(82)90428-2.

Kaza, N. (2015) 'Time dependent accessibility', Journal of Urban Management, 4(1), pp. 24-39. doi: 10.1016/j.jum.2015.06.001.

Kwan, M.-P. (2010) 'Space-Time and Integral Measures of Individual Accessibility: A Comparative Analysis Using a Point-based Framework', Geographical Analysis. Blackwell Publishing Ltd, 30(3), pp. 191-216. doi: 10.1111/j.1538-4632.1998.tb00396.x.

Kwon, J. et al. (2011) 'Decomposition of Travel Time Reliability into Various Sources', Transportation Research Record: Journal of the Transportation Research Board, 2229, pp. 28-33. doi: 10.3141/2229-04.

Lam, T. C. and Small, K. A. (2001) 'The value of time and reliability: measurement from a value pricing experiment', Transportation Research Part E: Logistics and Transportation Review, 37(2-3), pp. 231-251. doi: 10.1016/S1366-5545(00)00016-8.

Van Lint, J. and van Zuylen, H. (2005) 'Monitoring and Predicting Freeway Travel Time Reliability: Using Width and Skew of Day-to-Day Travel Time Distribution', Transportation Research Record, 1917(1), pp. 54-62. doi: 10.3141/1917-07.

Lomax, T. et al. (2003) SELECTING TRAVEL RELIABILITY MEASURES. Available at: 
https://static.tti.tamu.edu/tti.tamu.edu/documents/TTI-2003-3.pdf (Accessed: 28 August 2017).

Luo, W. and Wang, F. (2003) 'Measures of Spatial Accessibility to Health Care in a GIS Environment: Synthesis and a Case Study in the Chicago Region', Environment and Planning B: Planning and Design. SAGE PublicationsSage UK: London, England, 30(6), pp. 865-884. doi: 10.1068/b29120.

Miller, H. J. (2010) 'Measuring Space-Time Accessibility Benefits within Transportation Networks: Basic Theory and Computational Procedures', Geographical Analysis. Blackwell Publishing Ltd, 31(2), pp. 187-212. doi: 10.1111/j.1538-4632.1999.tb00976.x.

Moya-Gómez, B. et al. (2018) 'Dynamic Accessibility using Big Data: The Role of the Changing Conditions of Network Congestion and Destination Attractiveness', Networks and Spatial Economics. Springer US, 18(2), pp. 273-290. doi: 10.1007/s11067-017-9348-Z.

Moya-Gómez, B. and García-Palomares, J. C. (2015) 'Working with the daily variation in infrastructure performance on territorial accessibility. The cases of Madrid and Barcelona', European Transport Research Review. Springer International Publishing, 7(2), p. 20. doi: 10.1007/s12544-015-0168-2.

National Academies of Sciences, Engineering and Medicine (2012) Analytical Procedures for Determining the Impacts of Reliability Mitigation Strategies. Washington, D.C.: Transportation Research Board. doi: 10.17226/22806.

NHS (2018) Queen Elizabeth University Hospital. Available at: http://www.nhsggc.org.uk/patientsand-visitors/main-hospital-sites/queen-elizabeth-university-hospital-campus/queen-elizabethuniversity-hospital-glasgow/queen-elizabeth-university-hospital/\# (Accessed: 2 November 2018).

OECD and ITF (2010) Improving reliability on surface transport networks, Transport. doi: 10.1787/9789282102428-en.

Omer, M. (2013) The Resilience of Networked Infrastructure Systems. WORLD SCIENTIFIC. doi: $10.1142 / 8741$.

de Palma, A. and Picard, N. (2005) 'Route choice decision under travel time uncertainty', Transportation Research Part A: Policy and Practice. Pergamon, 39(4), pp. 295-324. doi: 10.1016/J.TRA.2004.10.001

Penchansky, R. and Thomas, J. W. (1981) 'The Concept of Access: Definition and Relationship to Consumer Satisfaction', Medical Care. Lippincott Williams \& Wilkins, pp. 127-140. doi: $10.2307 / 3764310$.

Polus, A. (1979) 'A study of travel time and reliability on arterial routes', Transportation. Kluwer Academic Publishers, 8(2), pp. 141-151. doi: 10.1007/BF00167196.

Pu, W. (2011) 'Analytic Relationships Between Travel Time Reliability Measures', Transportation Research Record: Journal of the Transportation Research Board. Transportation Research Board of the National Academies , 2254, pp. 122-130. doi: 10.3141/2254-13.

Rakha, H., El-Shawarby, I. and Arafeh, M. (2010) 'Trip Travel-Time Reliability: Issues and Proposed Solutions', Journal of Intelligent Transportation Systems. Taylor \& Francis Group , 14(4), pp. 232 250. doi: $10.1080 / 15472450.2010 .517477$.

Reggiani, A., Bucci, P. and Russo, G. (2011) 'Accessibility and Impedance Forms: Empirical Applications to the German Commuting Network', International Regional Science Review. SAGE PublicationsSage CA: Los Angeles, CA, 34(2), pp. 230-252. doi: 10.1177/0160017610387296.

Richardson, A. J. and Taylor, M. A. P. (1978) 'TRAVEL TIME VARIABILITY ON COMMUTER JOURNEYS', High Speed Ground Transportation Journal, 12(1). Available at: https://trid.trb.org/view/80100 (Accessed: 2 July 2018).

Roberts, A., Blunt, I. and Bardsley, M. (2014) Focus On: Distance from home to emergency care. Available at:

http://www.qualitywatch.org.uk/sites/files/qualitywatch/field/field_document/140218_QualityWatch_Fo cus_on_distance_emergency_care.pdf.

Socharoentum, M. and Karimi, H. A. (2015) 'A comparative analysis of routes generated by Web 
Mapping APIs', Cartography and Geographic Information Science. Taylor \& Francis, 42(1), pp. 33-43. doi: 10.1080/15230406.2014.976656.

Stępniak, M. et al. (2019) 'The impact of temporal resolution on public transport accessibility measurement: Review and case study in Poland', Journal of Transport Geography. Pergamon, 75, pp. 8-24. doi: 10.1016/J.JTRANGEO.2019.01.007.

Sterman, B. P. and Schofer, J. L. (1976) 'FACTORS AFFECTING RELIABILITY OF URBAN BUS SERVICES', ASCE Transp Eng J, 102(1), pp. 147-159. Available at:

https://www.scholars.northwestern.edu/en/publications/factors-affecting-reliability-of-urban-busservices (Accessed: 2 July 2018).

Susilawati, S., Taylor, M. A. P. and Somenahalli, S. V. C. (2013) 'Distributions of travel time variability on urban roads', Journal of Advanced Transportation, 47(8), pp. 720-736. doi: 10.1002/atr.192.

Tanser, F., Gijsbertsen, B. and Herbst, K. (2006) 'Modelling and understanding primary health care accessibility and utilization in rural South Africa: An exploration using a geographical information system', Social Science \& Medicine, 63(3), pp. 691-705. doi: 10.1016/j.socscimed.2006.01.015.

Taylor, M. A. P. (2013) 'Travel through time: the story of research on travel time reliability', Transportmetrica B: Transport Dynamics. Taylor \& Francis, 1(3), pp. 174-194. doi: 10.1080/21680566.2013.859107.

Taylor, M. A. P. and D'Este, G. M. (2007) 'Transport Network Vulnerability: a Method for Diagnosis of Critical Locations in Transport Infrastructure Systems', in Murray, A. T. and Grubesic, T. H. (eds) Critical Infrastructure. Berlin, Heidelberg: Springer Berlin Heidelberg, pp. 9-30. doi: 10.1007/978-3540-68056-7_2.

Taylor, M. A. P. and Susilawati (2012) 'Modelling Travel Time Reliability with the Burr Distribution', Procedia - Social and Behavioral Sciences, 54, pp. 75-83. doi: 10.1016/j.sbspro.2012.09.727.

Törnqvist, G. (1970) Contact systems and regional development. Edited by The Royal University of Lund. CWK Gleerup Publishers. Available at:

https://catalogue.sciencespo.fr/ark:/46513/sc0000796689 (Accessed: 16 August 2017).

Transport for London (2014) Travel and transport analysis for the NHS. London. Available at: http://content.tfl.gov.uk/travel-and-transport-analysis-in-the-nhs.pdf (Accessed: 9 August 2017).

Wang, F. (2000) 'Modeling Commuting Patterns in Chicago in a GIS Environment: A Job Accessibility Perspective', The Professional Geographer. Taylor \& Francis Group , 52(1), pp. 120-133. doi: 10.1111/0033-0124.00210.

Wang, F. and Luo, W. (2005) 'Assessing spatial and nonspatial factors for healthcare access: towards an integrated approach to defining health professional shortage areas', Health \& Place, 11, pp. 131146. doi: 10.1016/j.healthplace.2004.02.003.

Wang, F. and Xu, Y. (2011) 'Estimating O-D travel time matrix by Google Maps API: implementation, advantages, and implications', Annals of GIS, 17(4), pp. 199-209. doi: 10.1080/19475683.2011.625977.

Wang, J. Y. T. (2015) '"Resilience thinking” in transport planning', Civil Engineering and Environmental Systems, 32(1-2), pp. 180-191. doi: 10.1080/10286608.2015.1014810.

Weibull, J. W. (1976) 'An axiomatic approach to the measurement of accessibility', Regional Science and Urban Economics, 6(4), pp. 357-379. doi: 10.1016/0166-0462(76)90031-4.

Woodard, D. et al. (2017) 'Predicting travel time reliability using mobile phone GPS data', Transportation Research Part C: Emerging Technologies. Pergamon, 75, pp. 30-44. doi: 10.1016/J.TRC.2016.10.011. 